\title{
Solid State and Solution Structure of an Unusual Compound Containing a $\mathrm{CS}_{7}$ Ring
}

\author{
Heribert Offermanns*,a, Jürgen Martens ${ }^{\mathrm{b}}$, Martin Watzke $^{\mathrm{b}}$, Peter Albers*,c, Bernd Hannebauer ${ }^{\mathrm{c}}$, \\ Matthias Janik ${ }^{\mathrm{c}}$, Arndt Müller ${ }^{\mathrm{c}}$, Kenneth Shankland ${ }^{\mathrm{d}}$, Charlotte K. Leech ${ }^{\mathrm{d}}$ and Stewart F. Parker*,
}

${ }^{a}$ Grünaustraße 2, D-63457 Hanau, Germany; ${ }^{b}$ Institute for Pure and Applied Chemistry, University of Oldenburg, Ammerländer Heerstraße 114-118, D-26129 Oldenburg, Germany; ${ }^{c}$ AQura GmbH, Rodenbacher Chaussee 4, D-63457 Hanau, Germany; ${ }^{d}$ ISIS Facility, Rutherford Appleton Laboratory, Chilton, Didcot, Oxon, OX11 OQX, UK

\begin{abstract}
The structure of the product of the Asinger reaction of acetophenone with $n$-butylamine and elemental sulfur is still under debate. Two products have been proposed: a hexathiocanthione containing a $\mathrm{C}_{2} \mathrm{~S}_{6}$ ring with an exocyclic thione and a heptathiocane containing a $\mathrm{CS}_{7}$ ring. A single crystal X-ray study has shown that the heptathiocane structure is correct. ${ }^{1} \mathrm{H}$ and ${ }^{13} \mathrm{C}$ NMR investigations in solution confirm that the structure is maintained in solution and that there is no evidence for the imine tautomer.
\end{abstract}

\section{INTRODUCTION}

In the Asinger reaction of acetophenone with excess sulfur and primary amines sulfur-rich thiocanes are formed in high yields [1-4]. Using 1-aminobutane as the amino component, the product of the reaction is an intensely yellow crystalline solid with a melting point of $109-110^{\circ} \mathrm{C}$ and a sumformula of $\mathrm{C}_{12} \mathrm{H}_{15} \mathrm{~S}_{7}$. Fig. (1) shows three possible structures for the product: a hexathiocanthione, $\mathbf{1}$, an enamine ($\mathrm{C}=\mathrm{CR}-\mathrm{NH}-)$ heptathiocane, $\mathbf{2}$, and an imine $(-\mathrm{CH}-\mathrm{CR}=\mathrm{N}-)$ heptathiocane $\mathbf{2 a}$.<smiles>CC(=O)c1ccccc1</smiles>
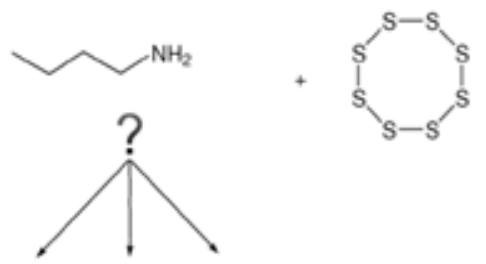

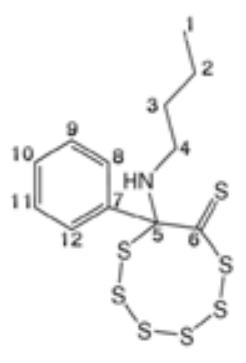

1

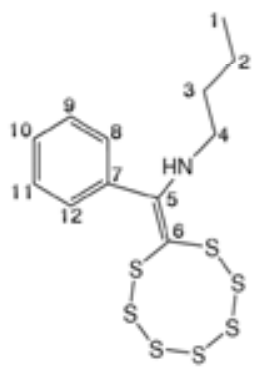

2

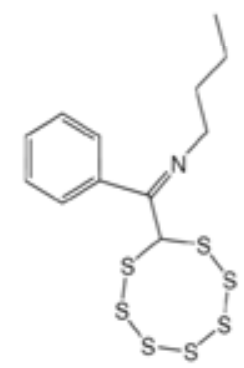

$2 a$
Fig. (1). Possible products of the Asinger reaction.

\footnotetext{
*Address correspondence to these authors at the Grünaustraße 2, D-63457 Hanau, Germany; E-mail: heppoff@gmx.de, AQura GmbH, Rodenbacher Chaussee 4, D-63457 Hanau, Germany; E-mail: peter.albers@aqura.de, ISIS Facility, Rutherford Appleton Laboratory, Chilton, Didcot, Oxon, OX11 0QX, UK; E-mail: stewart.parker@stfc.ac.uk
}

About 40 years ago, the structure of the thiocane was assigned from degradation reactions, together with results from the analytical methods available at that time by Asinger et al. as 8-butylamino-8-phenyl-1,2,3,4,5,6-hexathiocane-7thione, 1 [3]. Subsequent X-ray diffraction analysis of the crystal structure by Matschiner et al. [5] showed the presence of a heptathiocane, 8-(n-butylamino(phenyl)methylidene)-1,2,3,4,5,6,7-heptathiocane $\mathbf{2}$ (CCDC refcode: WIFPAC).

Previously, only the unsubstituted heptathiocane had been described in the literature [6] as a relatively unstable substance. Also, because it was not possible to use the product in reactions which are typical for enamines, we have carried out additional investigations to verify the structure. There is also an ongoing uncertainty as to whether the structure is the same in both the solid state and in solution (imine 2a).

The substance was prepared again according to Refs. [3] and [4] and was characterized in a new approach by means of XRD and NMR spectroscopies. The data are discussed in combination with results from $a b$ initio simulation techniques.

\section{EXPERIMENTAL}

\section{Elemental Analysis}

Found: C, 36.36; H, 3.68; N, 3.60; S 56.64\%.Calc. for $\mathrm{C}_{12} \mathrm{H}_{15} \mathrm{NS}_{7}$ : C, 36.24; H, 3.80; N, 3.52; S, 56.44\%.

\section{Mass Spectrometry}

The APCI mass spectrum of the solid shows a signal for $[\mathrm{MH}]+$ at $\mathrm{m} / \mathrm{z}=397.7$ Dalton corresponding to the molecular formula of $\mathrm{C}_{12} \mathrm{H}_{15} \mathrm{NS}_{7}$. In the MS/MS experiment the loss of six sulfur atoms is apparent.

\section{Single Crystal X-Ray Diffraction}

A plate-shaped crystal measuring $0.22 \times 0.15 \times 0.03 \mathrm{~mm}$ was mounted on an Oxford Diffraction Gemini diffractometer and diffraction data measured overnight at $123 \mathrm{~K}$ using Mo 
$\mathrm{K}_{\alpha}(\lambda=0.71073 \AA)$ radiation. The crystal structure was solved using SHELXS-97 and refined using SHELXL-97 [7]. All non-hydrogen atoms were located from the direct methods solution and all hydrogen atoms could be located from subsequent difference Fourier maps. The final refinement gave a $w R^{2}=0.095$. A second needle-like crystal was also measured and gave the same structure. CCDC 666611 contains the supplementary crystallographic data for this paper. These data can be obtained free of charge via www.ccdc.cam.ac.uk/conts/retrieving.html by e-mail: deposit@ccdc.cam.ac.uk), or from the Cambridge Crystallographic Data Centre, 12, Union Road, Cambridge CB2 1EZ, UK; (fax: +44 1223 336033).

\section{NMR Spectroscopy}

${ }^{1} \mathrm{H}$ and ${ }^{13} \mathrm{C}$ NMR spectra were recorded on a Bruker DRX 500 NMR spectrometer operating at $500.1 \mathrm{MHz}$ and $125.8 \mathrm{MHz}$ respectively. Both sets of spectra were recorded in $\mathrm{CDCl}_{3}$, if not otherwise stated, using tetramethylsilane $(0$ $\mathrm{ppm})$ as the internal standard. The broad band decoupled ${ }^{13} \mathrm{C}$ NMR spectrum was acquired with $6 \mathrm{k}$ transients.

The gradient selected proton carbon heteronuclear long range experiment (HMBC) was recorded with a spectral width of 12 and $240 \mathrm{ppm}$ in the ${ }^{1} \mathrm{H}$ and ${ }^{13} \mathrm{C}$ dimensions, respectively $[8,9] .128$ increments with 2048 complex data points and 32 transients were collected with a recycle delay of $1.5 \mathrm{~s}$. The raw data were multiplied by an unshifted sine function and Fourier transformed to obtain a final matrix of $2048 \times 1024$ real data points.

The ${ }^{1} \mathrm{H}$ to ${ }^{13} \mathrm{C}$ CP/MAS [10] solid state NMR spectra were recorded on a Bruker Avance $400 \mathrm{MHz}$ NMR spectrometer operating at $100.6 \mathrm{MHz} .624$ and 1347 transients with a contact time of $2 \mathrm{~ms}$, a spectral width of $400 \mathrm{ppm}$, a recycle delay of $5 \mathrm{~s}$ and rotational frequencies of $7 \mathrm{kHz}$ and 5 $\mathrm{kHz}$, respectively, were acquired. The spectrum was referenced externally against liquid $\mathrm{CDCl}_{3}$ at $77.0 \mathrm{ppm}$. The connectivity in the molecule and the assignment of the NMR spectra was proven by means of a heteronuclear long range coupling experiment (HMBC).

\section{$A b$ Initio Calculations}

The structures of $\mathbf{1}$ and $\mathbf{2}$ were first optimised using the B3LYP functional and the 6-311G(d) basis set as implemented in Gaussian 03 (rev B.05) [11]. The vibrational spectrum was also calculated to ensure that the structure was an energy minimum. The NMR spectra were then calculated using the GIAO method with the B3LYP functional and the 6-311G++(2d,p) basis set. The NMR spectra are referenced to tetramethylsilane calculated at the same levels.

\section{RESULTS AND DISCUSSION}

The solid state structure as determined by a single crystal $\mathrm{X}$-ray investigation is shown in Fig. (2). The structure is clearly that of the heptathiocane $\mathbf{2}$. The present work is in good agreement with the previous structure determination [5], albeit at higher resolution because of the lower temperature, $123 \mathrm{~K}$, used. There are no significant intermolecular contacts; the closest is at $2.575 \AA$ between the aromatic hydrogen atoms and the alkyl hydrogens. In particular, there is no evidence that the $\mathrm{N}-\mathrm{H}$ is involved in any hydrogen bonding. As noted previously, the geometry of the $\mathrm{CS}_{7}$ ring is very similar to that of $\mathrm{S}_{8}$ itself. The formal $\mathrm{C}=\mathrm{C}$ double bond between C5 and C6 is somewhat longer than usual at 1.386 A.

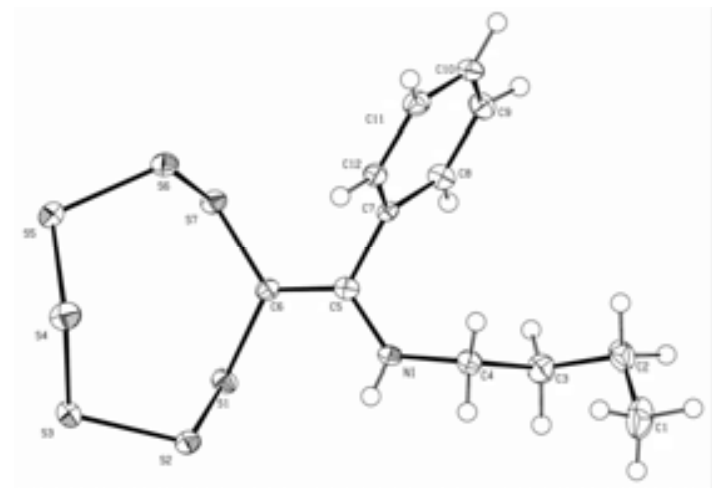

Fig. (2). Single crystal X-ray structure of the product of the reaction shown in Fig. (1).

To determine whether the solution and solid state structures were the same, solution ${ }^{1} \mathrm{H}$ and ${ }^{13} \mathrm{C}$ NMR spectra as well as ${ }^{13} \mathrm{C}$ solid state CPMAS NMR spectra were recorded. Figs. (3 and 4) show the spectra in solution, together with the $a b$ initio spectra calculated for both structures $\mathbf{1}$ and $\mathbf{2}$. Figs. (3 and 4) show that the same structure $\mathbf{2}$ is retained in solution. In particular, the amine hydrogen is observed at 6.30 $\mathrm{ppm}$, the $a b$ initio ${ }^{1} \mathrm{H}$ NMR of 2 predicts it at $6.28 \mathrm{ppm}$ whereas for $\mathbf{1}$ it is predicted at $1.50 \mathrm{ppm}$. In the ${ }^{13} \mathrm{C}$ NMR spectrum, the thione carbon is predicted at $262.09 \mathrm{ppm}$, while the lowest field peak is observed at $170.18 \mathrm{ppm}$ and is assigned to C5 (defined in Fig (2)). The imino structure 2a can be excluded in solution also because no aliphatic $\mathrm{CH}$ group is present in the spectra. Tables $\mathbf{1}$ and $\mathbf{2}$ give a complete list of the observed and calculated ${ }^{1} \mathrm{H}$ and ${ }^{13} \mathrm{C}$ NMR spectra for $\mathbf{1}$ and $\mathbf{2}$.

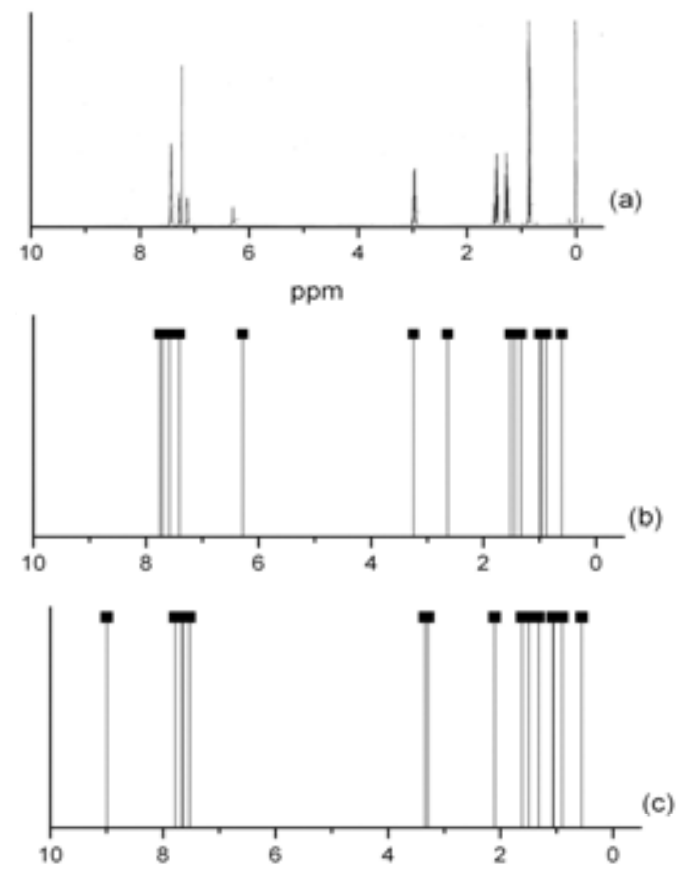

Fig. (3). Experimental (a) and ab initio ${ }^{1} \mathrm{H}$ NMR spectra for the two isomers of $\mathrm{C}_{12} \mathrm{H}_{17} \mathrm{NS}_{7}$ : (b) 2 and (c) 1 . (The peak at $7.25 \mathrm{ppm}$ in (a) is due to $\mathrm{CHCl}_{3}$ in the $\mathrm{CDCl}_{3}$ solvent). 

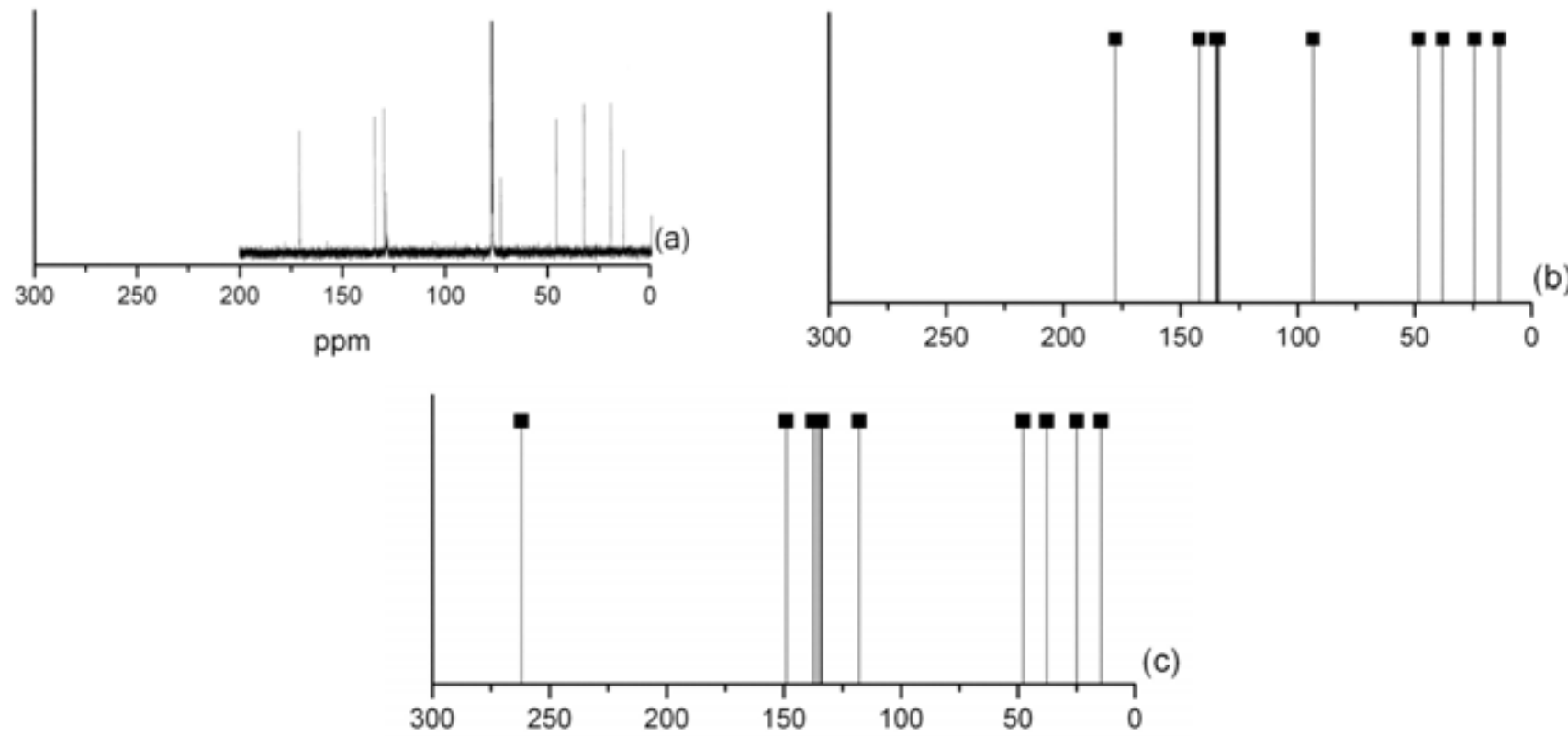

Fig. (4). Experimental (a) and ab initio ${ }^{13} \mathrm{C}$ NMR spectra for the isomers of $\mathrm{C}_{12} \mathrm{H}_{17} \mathrm{NS}$ : (b) 2 and (c) 1 .

Table 1. Experimental and $a b$ initio ${ }^{1} \mathrm{H}$ nmr chemical shifts for the two Isomers of $\mathrm{C}_{12} \mathrm{H}_{17} \mathrm{NS}_{7}$. All shifts are relative to tetramethylsilane. The numbering scheme is given in Fig. (1)

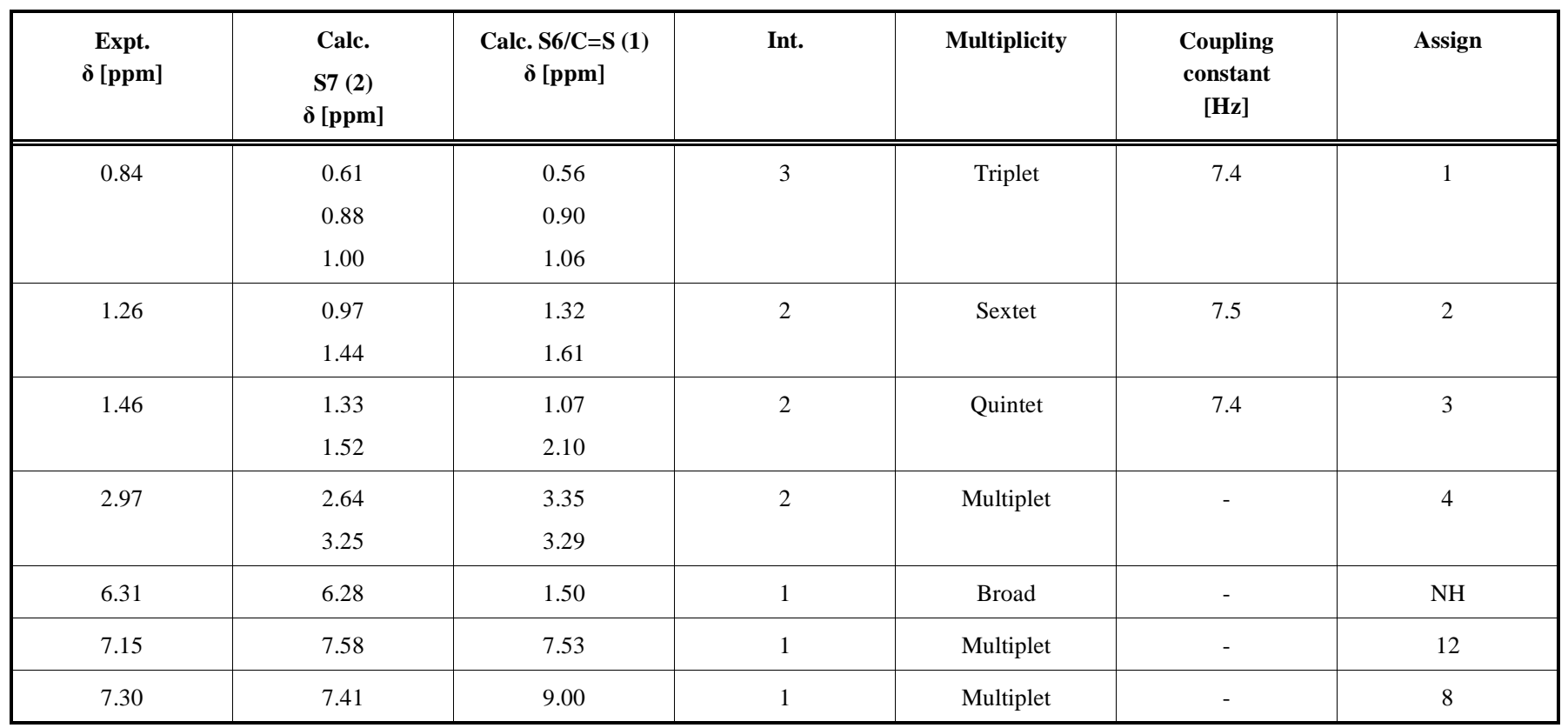

Table 2. Experimental and $a b$ initio ${ }^{13} \mathrm{C}$ nmr chemical shifts for the two Isomers of $\mathrm{C}_{12} \mathrm{H}_{17} \mathrm{NS}_{7}$. All shifts are relative to tetramethylsilane. The numbering scheme is given in Fig. (1)

\begin{tabular}{|c|c|c|c|}
\hline $\begin{array}{c}\text { Expt. } \\
\boldsymbol{\delta}[\mathbf{p p m}]\end{array}$ & $\begin{array}{c}\text { Calc. S7 (2) } \\
\boldsymbol{\delta}[\mathbf{p p m}]\end{array}$ & $\begin{array}{c}\text { Calc. S6/C=S (1) } \\
\boldsymbol{\delta}[\mathbf{p p m}]\end{array}$ & \begin{tabular}{c} 
Assignment \\
\hline 13.60
\end{tabular} \\
\hline \hline 19.65 & 13.83 & 14.52 & 1 \\
\hline 32.62 & 24.38 & 24.92 & 3 \\
\hline 45.96 & 37.98 & 37.75 & 4 \\
\hline
\end{tabular}


(Table 2). Contd.....

\begin{tabular}{|c|c|c|c|}
\hline $\begin{array}{c}\text { Expt. } \\
\delta[p p m]\end{array}$ & $\begin{array}{c}\text { Calc. S7 (2) } \\
\delta[p p m]\end{array}$ & $\begin{array}{c}\text { Calc. } S 6 / C=S(1) \\
\delta[p p m]\end{array}$ & Assignment \\
\hline 72.15 & 93.37 & 262.09 & 6 \\
\hline 127.59 & 133.79 & 136.09 & 8 \\
\hline 128.19 & 134.09 & 133.86 & 9 \\
\hline 128.61 & 134.09 & 134.06 & 11 \\
\hline 128.74 & 134.76 & 134.34 & 10 \\
\hline 129.40 & 134.98 & 137.55 & 12 \\
\hline 133.72 & 141.94 & 149.05 & 7 \\
\hline 170.20 & 177.78 & 117.86 & 5 \\
\hline
\end{tabular}

Remarkable is the non-equivalence of the benzene ring nucleii in the NMR spectra, due to hindered rotation. Also the multiplet structure of the protons at $\mathrm{C} 4$ shows a small degree of non-equivalence. ${ }^{1} \mathrm{H}$ NMR spectra in tetrachloroethene show coalescence of the aromatic protons $\mathrm{H} 8$ and $\mathrm{H} 12$ at $353 \mathrm{~K}$.

\section{CONCLUSIONS}

This work has shown unambiguously that the product of the reaction shown in Fig. (1) is the heptathiocane $\mathbf{2}$ and that this structure is retained in solution. This conclusion is supported by the calculations which show 2 to be $1.14 \mathrm{eV}$ lower in energy than $\mathbf{1}$. A longstanding debate has been resolved.

\section{REFERENCES}

[1] Asinger, F. Angew. Chem., 1956, 68, 377.

[2] Asinger, F.; Offermanns, H. Angew. Chem. Int. Ed., 1967, 6, 907919.

[3] Asinger, F.; Becker, H.W.; Schäfer, W.; Saus, A. Monatsh. Chem., 1966, 97, 301 .

[4] Asinger, F.; Saus, A.; Offermanns, H.; Abo Dagga, F. Liebigs Ann. Chem., 1969, 723, 119-128.

[5] Heinemann, F.W.; Hartung, H.; Maier, N. Matschiner, H. Z. Naturforsch., 1994, 49b, 1063-1066.
[6] Feher, F.; Becher, W.; Z. Naturforsch., 1965, 20b, 1125-1129.

[7] Sheldrick, G.M. SHELXS97 and SHELXL97. University of Göttingen, Germany, 1997.

[8] Bax, A.; Summers, M.F. J. Am. Chem. Soc., 1986, 108, 2093-2094.

[9] Willker, W.; Leibfritz, D.; Kerssebaum, R.; Bermel, W. Magn. Reson. Chem., 1993, 31, 287-292.

[10] Pines, A.; Gibby, M.G.; Waugh, J.S. J. Chem. Phys., 1972, 56, 1776-1777.

[11] Frisch, M. J.; Trucks, G. W.; Schlegel, H. B.; Scuseria, G. E.; Robb, M. A.; Cheeseman, J. R.; Montgomery, J. A., Jr.; Vreven, T.; Kudin, K. N.; Burant, J. C.; Millam, J. M.; Iyengar, S. S.; Tomasi, J.; Barone, V.; Mennucci, B.; Cossi, M.; Scalmani, G.; Rega, N.; Petersson, G. A.; Nakatsuji, H.; Hada, M.; Ehara, M.; Toyota, K.; Fukuda, R.; Hasegawa, J.; Ishida, M.; Nakajima, T.; Honda, Y.; Kitao, O.; Nakai, H.; Klene, M.; Li, X.; Knox, J. E.; Hratchian, H. P.; Cross, J. B.; Adamo, C.; Jaramillo, J.; Gomperts, R.; Stratmann, R. E.; Yazyev, O.; Austin, A. J.; Cammi, R.; Pomelli, C.; Ochterski, J. W.; Ayala, P. Y.; Morokuma, K.; Voth, G. A.; Salvador, P.; Dannenberg, J. J.; Zakrzewski, V. G.; Dapprich, S.; Daniels, A. D.; Strain, M. C.; Farkas, O.; Malick, D. K.; Rabuck, A. D.; Raghavachari, K.; Foresman, J. B.; Ortiz, J. V.; Cui, Q.; Baboul, A. G.; Clifford, S.; Cioslowski, J.; Stefanov, B. B.; Liu, G.; Liashenko, A.; Piskorz, P.; Komaromi, I.; Martin, R. L.; Fox, D. J.; Keith, T.; AlLaham, M. A.; Peng, C. Y.; Nanayakkara, A.; Challacombe, M.; Gill, P. M. W.; Johnson, B.; Chen, W.; Wong, M. W.; Gonzalez, C.; Pople, J. A. Gaussian 03, Revision B.05; Gaussian, Inc.: Pittsburgh, PA, 2003.

Received: April 06, 2008

(C) Offermanns et al.; Licensee Bentham Open.

This is an open access article licensed under the terms of the Creative Commons Attribution Non-Commercial License (http://creativecommons.org/licenses/by-nc/3.0/) which permits unrestricted, non-commercial use, distribution and reproduction in any medium, provided the work is properly cited. 